\title{
Impact of Water Stress on Root Architecture in Tomato (Solanum lycopersicum Mill)
}

\author{
M. Senthilkumar ${ }^{1 *}$, A.T. Sadashiva ${ }^{1}$ and V. Laxmanan ${ }^{2}$ \\ ${ }^{1}$ Division of Vegetable Crops, ICAR-Indian Institute of Horticultural Research, \\ Bengaluru-89, Karnataka, India \\ ${ }^{2}$ Horticultural College and Research Institute, T.N.A.U, Periyakulam-625 604, \\ Tamil Nadu, India \\ *Corresponding author
}

\begin{tabular}{|c|c|}
\hline & A B S T R A C T \\
\hline & An experiment was carried out at Horticultural College and Research Institute Periyakulam \\
\hline & $\begin{array}{l}\text { to study the impact of water stress on root architecture in Tomato (Solanum lycopersicum } \\
\text { Mill). Three popular varieties of south India viz., PKM-1, Arka Vikas and Arka Meghali }\end{array}$ \\
\hline $\begin{array}{l}\text { Tomato, Root } \\
\text { architecture, Water } \\
\text { stress, Controlled } \\
\text { irrigation. }\end{array}$ & $\begin{array}{l}\text { were taken as study material. The experiment was carried out under controlled irrigation at } \\
50 \text { per cent and } 100 \text { per cent field capacity. The data collected at } 20^{\text {th }} \text { and } 40^{\text {th }} \text { day after } \\
\text { transplanting on root characters such as root weight, root length and root volume revealed } \\
\text { that among the three cultivars Arka Vikas and PKM-1 are comparatively tolerant towards }\end{array}$ \\
\hline Article Info & $\begin{array}{l}\text { water stress at } 40 \text { days as compared to Arka Meghali. The variety PKM-1 recorded } 2.15 \\
\text { times higher root weight, } 1.26 \text { times higher root length, } 3.33 \text { times higher root volume at }\end{array}$ \\
\hline $\begin{array}{l}\text { Accepted: } \\
\text { 21 June } 2017 \\
\text { Available Online: } \\
10 \text { July } 2017\end{array}$ & $\begin{array}{l}50 \% \text { field capacity as compared to } 100 \% \text { field capacity. Similarly Arka Vikas recorded } \\
1.80 \text { times higher root weight, } 1.42 \text { times higher root length and } 1.66 \text { times higher root } \\
\text { volume at } 50 \% \text { field capacity compared to } 100 \% \text { field capacity. The variety PKM-1 which } \\
\text { is very popular and commercially grown not only in Tamil Nadu but also in adjoining } \\
\text { states has shown higher level of tolerance towards water stress followed by Arka Vikas. }\end{array}$ \\
\hline
\end{tabular}

\section{Introduction}

Tomato (Solanum lycopersicum Mill) is one of the most wanted vegetables all over the world both for the fresh fruit market and processed food industries. The fruits are eaten raw or cooked as it plays a vital role in providing a substantial quantity vitamin $\mathrm{C}$ and $\mathrm{A}$ in human diet. It is very much preferred as salad, made into soups, juice, ketchup, pickles, sauces, puree, paste, powder and other products. In the successful cultivation of Tomato, water plays an important role in determining the plant growth and yield (Alaoui et al., 2014).
They are very sensitive to water deficits during and immediately after transplanting, at flowering and also during fruit development. The water stress at earlier stage of growth (20 day stage) is highly inhibitory compared to the later stage (30 day stage) (Nuruddin, 2001).

Water stress reduces yield due to reduction in the nutrient uptake. Moreover, proper time of irrigation is essential for the production of the most of the vegetables. If water shortage occurs in the early crop development, 
maturity may be delayed which may reduce yield. Thus, it needs a controlled supply of water throughout the growing period for higher yield and optimal quality (Shamsul et al., 2008).

Generally the photosynthetic response of plants to drought is a highly complex one. Water deficit inhibits photosynthesis by causing stomatal closure and metabolic damage. Stomata of the leaves which are slightly deficient in water open more slowly in light and close more quickly in the dark (Nuruddin, 2001). Soil moisture stress reduces leaf water potential and in turn reduces transpiration (Morison et al., 2008). It also results in significant decrease in chlorophyll content, electrolyte leakage, leaf relative water content and vegetative growth; and plants grown under high water stress have less fruit yield and quality (Kirnak et al., 2001). Nyabundi and Hsiao, 2009 observed that, Tomato plants subjected to different levels of water stress under field conditions had inhibited vegetative growth but enhanced fruit development and the plants tend to grow a denser root system at soil water potentials which are slightly less than field capacity (Nuruddin, 2001). Whereas, Alaoui et al., 2014 observed that water stress conditions encourage tomato to develop deeper roots, a natural moisture searching mechanism, especially on sandy soils. Thus, plant water status controls the physiological process and conditions, which determine the quantity and quality of its growth.

India is having a total area 882 Million ha with a production of 18735.9 Million tonnes and it is grown in all the states (Anonymous, 2013). Tamil Nadu produces 726524 Metric tonnes from an area of 31647 ha. It is expected that in the next decade, several countries in the arid and semiarid region of the globe will be under water scarcity. It is also predicted that the world population will be double in the next 50 years, so greater yield should be realised from the current agricultural area (Alaoui et al., 2014) to fulfil the need of the growing population. In the present context, drought is considered as a major abiotic stress factor limiting crop productivity worldwide. As water resource for agricultural use become more limiting, the development of drought-tolerant lines in vegetables like tomato will become increasingly important. Another, aspect of principal importance in this line is to study the root growth and development of the existing important tomato varieties under water-deficit conditions for better utilization of such varieties in the near future.

In south India, tomato varieties viz., PKM-1, Arka Vikas, Arka Megahli are very popular among the farmers for their reasonable cost of cultivation and yield. As water deficit is recognized as one of the major abiotic stress factors limiting agricultural production worldwide and tomato requires adequate water for its production, it was felt necessary to study the effect of water stress in the production system of tomato by critically studying the root architecture.

Therefore as a first step, the present investigation was undertaken to study some of the morphological parameters viz., root and shoot development of tomato plants as affected by water stress at the initial stages of its growth.

\section{Materials and Methods}

The study entitled "Impact of water stress on root architecture in Tomato (Solanum lycopersicum Mill)" was carried out in the year 2015 at the Horticulture College and Research Institute, Tamil Nadu Agricultural University, Periyakulam-625 604 which is situated at $10.13^{\circ}$ North latitude and $77.59^{\circ}$ longitude at an altitude of 289 metres above mean sea level. The mean maximum and minimum temperature of the experimental 
location was $36^{\circ} \mathrm{C}$ and $25^{\circ} \mathrm{C}$ respectively with a relative humidity of 74 per cent. The average rain fall is around $730 \mathrm{~mm}$.

\section{Experiment details}

The treatments comprised of two levels of irrigation (100\% field capacity and 50\% field capacity) with three varieties viz., PKM-1, Arka Meghali and Arka Vikas. The experiment was laid out in a Factorial Randomised Block design (2 factors x 3 levels) with three replications.

\section{Experimental plots}

Six concrete blocks admeasuring $1.20 \mathrm{~m}$ (Length) x $0.84 \mathrm{~m}$ (Width) x $0.60 \mathrm{~m}$ (Depth) were constructed and each was filled uniformly with $800 \mathrm{~kg}$ of river sand sieved through $3 \mathrm{~mm}$ iron wire mesh. A known quantity of sieved sand was taken and the $100 \%$ field capacity was arrived. Based on this the field capacity of the blocks were calculated.

This experimental plot was covered by an overhead shed made up of transparent polythene sheets to avoid rain contacting the plots.

\section{Nursery and planting}

Seeds were sown in the protrays and uniform sized seedlings ( 25 days old) were transplanted on 14-08-2015. The nutrients was applied through foliar sprays on alternate days using 19:19:19 based on the recommendation of Tamil Nadu Agricultural University (i.e., 150:100:50 $\mathrm{kg}_{\text {of NPK ha }}{ }^{-1}$ ).

\section{Intercultural operations}

Watering was done on daily basis, maintaining the $100 \%$ and $50 \%$ field capacities as per the treatments. Weeds were removed at regular intervals and plant protection measures were taken as and when the condition warranted.

\section{Biometric observations}

The biometric observations such as number of leaflets, plant height, total fresh plant weight, root length, fresh root weight were taken at 20 and 40 days after planting as per the standard procedure. Similarly the root volume was measured using the water displacement method and expressed in $\mathrm{cm}^{3}$. The whole plant was separated into leaves, stem and root and their weights were recorded. The samples were dried in the oven at $65^{\circ} \mathrm{C}$ and the dry weights were recorded and expressed in $\mathrm{g}$ plant $^{-1}$. The data were analyzed using Web Agri Stat Package version WASP 1.0 developed by the Indian Council of Agricultural Research Complex, Goa. Treatment difference was evaluated using least significant difference (LSD) at $\mathrm{p} \geq 0.05$.

\section{Results and Discussion}

\section{Morphological characters}

\section{Plant height}

At 20 days after planting the plant height was higher in the plants given irrigation at 50\% field capacity. Similar trend was observed at 40 days after planting (Table 1). Among the varieties PKM-1 recorded highest height (25.51 and $33.85 \mathrm{~cm}$ ) at $100 \%$ and $50 \%$ field capacities at 20 days after planting, whereas at 40 days after planting, Arka Vikas recorded the highest plant height of 82 and $115 \mathrm{~cm}$ under $100 \%$ and $50 \%$ field capacity respectively.

Among the varieties the PKM-1 considered to be determinate while Arka Meghali and Arka Vikas represent semi and indeterminate types. Therefore, though the initial plant height was 
higher in the case of PKM-1, the other varieties have subsequently grown at a faster rate and recorded higher values for height at 40 days.

Besides, as compared to $100 \%$ field capacity, the height at $50 \%$ field capacity was higher at 20 and 40 days giving an indication of their suitability for growing under water stress condition. The better performance under $50 \%$ can be interpreted that this level of stress may not limit the growth of PKM-1 and Arka Vikas. Whereas, May (1993) indicated that low stress levels resulted in maximum yields in tomato, while high stress resulted in the lowest yields.

\section{Number of leaflets}

Among the varieties PKM-1 recorded higher number of leaflets (9.41 and 68) at 20 and 40 days followed by Arka Meghali and Arka Vikas. Among the two levels of irrigation $50 \%$ field capacity has recorded higher mean value at 20 and 40 days (Table 2).

In the varieties, PKM-1 and Arka Vikas, the number of leaflets was higher at $50 \%$ field capacity whereas in the case of Arka Meghali, it was higher only at $100 \%$ field capacity. The overall performance indicated that the varieties PKM-1 and Arka Vikas produced more leaflets even at water stress, whereas Arka Megahli experienced stress and resulted in less number of leaflets.

\section{Total plant weight}

At 20 days after planting all the varieties recorded higher plant weight at 50\% field capacity and at 40 days after planting also PKM-1, Arka Vikas continued the same trend recording 596 and 354 g plant $^{-1}$ respectively (Table 3). Arka Meghali recorded higher value for plant weight $\left(284 \mathrm{~g} \mathrm{plant}^{-1}\right)$ at $100 \%$ field capacity but the weight was considerably reduced at $50 \%$ field capacity with a value of $145 \mathrm{~g}$ plant $^{-1}$. The variety mean indicated that PKM-1 recorded the highest plant weight both at 20 and 40 days followed by Arka Vikas and the lowest value was recorded with Arka Meghali.

The above results revealed that water stress did not affect the growth of the varieties PKM-1 and Araka Vikas and particularly their performance was not hindered under water stress, whereas in the case of Arka Meghali though the weight under 50\% field condition was higher as compared to $100 \%$ field capacity at 20 days after planting the condition was reverse at 40 days after planting, as reduction in the plant weight was observed at $50 \%$ field capacity.

This can also be inferred that water is not limiting for the growth of Arka Meghali up to 20 days after transplanting but water plays very vital role when the plant enters into the flowering phase.

\section{Dry matter production (\%)}

At 20 days after planting the dry matter per cent was higher in Arka Vikas (39.09 per cent) at $100 \%$ field capacity and higher in Arka Meghali (26.11 per cent) at $50 \%$ field capacity. At this stage, the variety mean indicated that the dry matter percentage was higher in Arka Vikas followed by Arka Meghali and PKM-1. At 40 days after planting the dry matter percentage was higher at $100 \%$ field capacity irrespective of the varieties as compared to $50 \%$ field capacity. Among the varieties Arka Meghali recorded higher dry matter percentage at both the field capacities (Table 4).

\section{Dry matter content}

The influence of water stress on total dry matter production was estimated at 20 and 40 
days after planting and the details are given in table 5. It was observed that at 20 days, there was slight reduction in the total dry matter content in all the varieties at $50 \%$ field capacity.

However, at 40 days after planting PKM-1 recorded more dry matter under water stress condition. There was a 3 fold increase in the dry matter production in PKM-1 and 2 fold increase in Arka Vikas.

However, surprisingly Arka Meghali shown a drastic reduction in the total dry matter production due to water stress.

The dry matter produced by the plants due to stress was dependent on variety.

This influence of water stress can be viewed as an impact factor in limiting the growth and development. As regards to PKM-1, Arka Vikas, they showed some promising results by recording more dry matter content even under moisture stress.

However, this needs further critical evaluation to confirm the varietal reaction as far as stress is concerned. The interaction effect of water deficit and cultivars was highly significant in dry matter production.

Contrary to the findings of Aragon, (1988); Ingram and Yambao, (1988) in rice, the varieties PKM-1 and Arka Vikas recorded higher dry matter production under water stress condition which needs further confirmation.

Brdar Jokanovic et al., (2014) reported higher root fractions in the total dry weight increased at drought for $68.2 \%$ on an average. Shoot and root dry weights were positively correlated at optimal irrigation but not in drought, implying genotypic differences in terms of root adjustments to stress conditions.

Three tomato varieties viz., PKM-1, Arka Meghali and Arka Vikas had formed the study material. The general characters of these varieties are given below

\begin{tabular}{|l|l|}
\hline \multicolumn{1}{|c|}{ Variety } & \multicolumn{1}{c|}{ Characters } \\
\hline PKM-1 & $\begin{array}{l}\text { It is an induced mutant from a local variety called Annanji. The fruits are } \\
\text { flat round with prominent green shoulder and capsicum red colour. It is } \\
\text { suitable for long distance transport. It yields about 30-35 tonnes ha' in a } \\
\text { crop duration of 135 days. This variety was evolved at the then } \\
\text { Horticultural Research Station, Periyakulam (Now Horticultural College } \\
\text { and Research Institute) }\end{array}$ \\
\hline Arka Meghali & $\begin{array}{l}\text { A pedigree selection (F8) of the cross Arka Vikas x IIHR 554 and released } \\
\text { by Indian Institute of Horticultural Research, Bangalore. Plants are semi } \\
\text { determinate. Narrow dark green leaves with good canopy. Fruits medium } \\
\text { sized (65 g), oblate with light green shoulder. Deep red fruits. Suitable for } \\
\text { fresh market. Bred for rainfed cultivation. Suitable for Khariff season. } \\
\text { Duration 125 days. Yield 18 tha }\end{array}$ \\
\hline Arka Vikas & $\begin{array}{l}\text { It is an improvement over an introduced variety "Tip Top". It was evolved } \\
\text { at Indian Institute of Horticultural Research, Bangalore. It is an } \\
\text { indeterminate variety. Fruits are medium large (80-90 g), oblate with light } \\
\text { green shoulder, which develop deep red on ripening. Developed for fresh } \\
\text { market Adapted to both rainfed and irrigated conditions. Average yield 35 } \\
\text { t/ha in 110-115 days. }\end{array}$ \\
\hline
\end{tabular}


Table.1 Effect of water stress on plant height in tomato $(\mathrm{cm})$

\begin{tabular}{|c|c|c|c|c|c|c|}
\hline \multirow[b]{2}{*}{ Varieties } & \multicolumn{3}{|c|}{20 DAP } & \multicolumn{3}{|c|}{40 DAP } \\
\hline & $100 \%$ F.C & $\mathbf{5 0} \%$ F.C & $\begin{array}{l}\text { Variety } \\
\text { Mean }\end{array}$ & $100 \%$ F.C & $50 \%$ F.C & $\begin{array}{l}\text { Variety } \\
\text { Mean }\end{array}$ \\
\hline PKM- 1 & 25.51 & 33.85 & 29.68 & 62.00 & 72.00 & 67.00 \\
\hline Arka Meghali & 27.00 & 21.00 & 24.00 & 72.00 & 72.00 & 72.00 \\
\hline Arka Vikas & 21.38 & 30.00 & 25.69 & 82.00 & 115.00 & 98.50 \\
\hline Treatment Mean & 24.63 & 28.28 & - & 72.00 & 86.33 & - \\
\hline & $\mathrm{T}$ & $\mathrm{V}$ & $\mathrm{TxV}$ & $\mathrm{T}$ & $\mathrm{V}$ & $\mathrm{TxV}$ \\
\hline S.Em \pm & 0.002 & 0.002 & 0.004 & 0.88 & 1.07 & 1.53 \\
\hline C.D at 5\% & 0.005 & 0.006 & 0.009 & 2.20 & 2.67 & 3.82 \\
\hline
\end{tabular}

Table.2 Effect of water stress on number of leaflets in tomato

\begin{tabular}{|l|l|l|l|l|l|l|}
\hline \multirow{2}{*}{ Varieties } & \multicolumn{5}{|c|}{$\mathbf{2 0}$ DAP } & \multicolumn{3}{|c|}{ 40 DAP } \\
\cline { 2 - 7 } & $\mathbf{1 0 0} \%$ F.C & $\mathbf{5 0} \%$ F.C & $\begin{array}{c}\text { Variety } \\
\text { Mean }\end{array}$ & $\mathbf{1 0 0} \%$ F.C & $\mathbf{5 0}$ \% F.C & $\begin{array}{c}\text { Variety } \\
\text { Mean }\end{array}$ \\
\hline PKM- 1 & 8.25 & 10.57 & 9.41 & 41.00 & 95.00 & 68.00 \\
\hline Arka Meghali & 8.33 & 7.65 & 7.99 & 34.00 & 27.00 & 30.50 \\
\hline Arka vikas & 6.14 & 7.38 & 6.76 & 24.00 & 35.00 & 29.50 \\
\hline Treatment Mean & 7.57 & 8.53 & - & 33.00 & 52.33 & - \\
\hline & $\mathrm{T}$ & $\mathrm{V}$ & $\mathrm{TxV}$ & $\mathrm{T}$ & $\mathrm{V}$ & TxV \\
\hline S.Em \pm & 0.15 & 0.18 & 0.26 & 1.06 & 1.30 & 1.84 \\
\hline C.D at 5\% & 0.43 & 0.52 & 0.74 & 3.02 & 3.70 & 5.23 \\
\hline DAP- Days after planting, F.C-Field capacity, T-Treatment, V-Variety & \\
\hline
\end{tabular}

Table.3 Effect of water stress on total plant weight in tomato $(\mathrm{g})$

\begin{tabular}{|l|l|l|l|l|l|l|}
\hline \multirow{2}{*}{ Varieties } & \multicolumn{5}{|c|}{20 DAP } & \multicolumn{3}{c|}{40 DAP } \\
\cline { 2 - 7 } & $\mathbf{1 0 0} \%$ F.C & $\mathbf{5 0} \%$ F.C & $\begin{array}{c}\text { Variety } \\
\text { Mean }\end{array}$ & $\mathbf{1 0 0}$ \% F.C & $\mathbf{5 0} \%$ F.C & $\begin{array}{c}\text { Variety } \\
\text { Mean }\end{array}$ \\
\hline PKM- 1 & 18.00 & 25.33 & $\mathbf{2 1 . 6 7}$ & 186.00 & 596.00 & $\mathbf{3 9 1 . 0 0}$ \\
\hline Arka Meghali & 12.00 & 20.33 & $\mathbf{1 6 . 1 7}$ & 284.00 & 145.00 & $\mathbf{2 1 4 . 5 0}$ \\
\hline Arka vikas & 16.33 & 20.00 & $\mathbf{1 8 . 1 7}$ & 149.00 & 354.00 & $\mathbf{2 5 1 . 5 0}$ \\
\hline Treatment Mean & $\mathbf{1 5 . 4 4}$ & $\mathbf{2 1 . 8 9}$ & - & $\mathbf{2 0 6 . 3 3}$ & $\mathbf{3 6 5 . 0 0}$ & - \\
\hline & $\mathrm{T}$ & $\mathrm{V}$ & $\mathrm{TxV}$ & $\mathrm{T}$ & $\mathrm{V}$ & $\mathrm{TxV}$ \\
\hline S.Em \pm & 0.36 & 0.45 & 0.63 & 7.68 & 9.41 & 13.31 \\
\hline C.D at 5\% & 1.03 & 1.27 & 1.79 & 21.90 & 26.82 & 37.93 \\
\hline DAP- Days after planting, F.C-Field capacity, T-Treatment, V-Variety \\
\hline
\end{tabular}

Table.4 Effect of water stress on dry matter in tomato (\%)

\begin{tabular}{|l|l|l|l|l|l|l|}
\hline \multirow{2}{*}{ Varieties } & \multicolumn{5}{|c|}{$\mathbf{2 0}$ DAP } & \multicolumn{3}{c|}{ 40 DAP } \\
\cline { 2 - 7 } & $\mathbf{1 0 0} \%$ F.C & $\mathbf{5 0} \%$ F.C & $\begin{array}{c}\text { Variety } \\
\text { Mean }\end{array}$ & $\mathbf{1 0 0} \%$ F.C & $\mathbf{5 0}$ \% F.C & $\begin{array}{c}\text { Variety } \\
\text { Mean }\end{array}$ \\
\hline PKM- 1 & 32.94 & 23.60 & $\mathbf{2 8 . 2 7}$ & 23.51 & 20.46 & $\mathbf{2 1 . 9 9}$ \\
\hline Arka Meghali & 30.90 & 26.11 & $\mathbf{2 8 . 5 0}$ & 28.29 & 24.07 & $\mathbf{2 6 . 1 8}$ \\
\hline Arka vikas & 39.09 & 24.21 & $\mathbf{3 1 . 6 5}$ & 27.00 & 21.29 & $\mathbf{2 4 . 1 5}$ \\
\hline Treatment Mean & $\mathbf{3 4 . 3 1}$ & $\mathbf{2 4 . 6 4}$ & - & $\mathbf{2 6 . 2 7}$ & $\mathbf{2 1 . 9 4}$ & - \\
\hline & $\mathrm{T}$ & $\mathrm{V}$ & TxV & T & V & TxV \\
\hline S.Em \pm & 0.35 & 0.44 & 0.62 & 0.42 & 0.52 & 0.73 \\
\hline C.D at 5\% & 1.01 & 1.25 & 1.76 & 1.21 & 1.48 & 2.09 \\
\hline DAP- Days after planting, F.C-Field capacity, T-Treatment, V-Variety & \\
\hline
\end{tabular}


Table.5 Effect of water stress on dry matter content in tomato $\left(\mathrm{g}\right.$ plant $\left.{ }^{-1}\right)$

\begin{tabular}{|l|l|l|l|l|l|l|}
\hline \multirow{2}{*}{ Varieties } & \multicolumn{3}{|c|}{$\mathbf{2 0}$ DAP } & \multicolumn{3}{|c|}{ 40 DAP } \\
\cline { 2 - 7 } & $\mathbf{1 0 0} \%$ F.C & $\mathbf{5 0} \%$ F.C & $\begin{array}{c}\text { Variety } \\
\text { Mean }\end{array}$ & $\mathbf{1 0 0}$ \% F.C & $\mathbf{5 0} \%$ F.C & $\begin{array}{c}\text { Variety } \\
\text { Mean }\end{array}$ \\
\hline PKM- 1 & 5.93 & 5.9 & $\mathbf{5 . 9 2}$ & 43.73 & 121.94 & $\mathbf{8 2 . 8 4}$ \\
\hline Arka Meghali & 3.4 & 4.69 & $\mathbf{4 . 0 5}$ & 80.34 & 34.90 & $\mathbf{5 7 . 6 2}$ \\
\hline Arka vikas & 4.3 & 4.76 & $\mathbf{4 . 5 3}$ & 40.23 & 75.37 & $\mathbf{5 7 . 8 0}$ \\
\hline Treatment Mean & $\mathbf{4 . 5 4}$ & $\mathbf{5 . 1 2}$ & & $\mathbf{5 4 . 7 7}$ & $\mathbf{7 7 . 4 0}$ & \\
\hline & $\mathrm{T}$ & $\mathrm{V}$ & $\mathrm{TxV}$ & $\mathrm{T}$ & $\mathrm{V}$ & TxV \\
\hline S.Em \pm & 0.09 & 0.12 & 0.18 & 1.04 & 1.27 & 1.80 \\
\hline C.D at 5\% & 0.27 & 0.35 & 0.50 & 2.96 & 3.62 & 5.12 \\
\hline DAP- Days after planting, F.C-Field capacity, T-Treatment, V-Variety \\
\hline
\end{tabular}

Table.6 Effect of water stress on fresh root weight in tomato $(\mathrm{g})$

\begin{tabular}{|l|l|l|l|l|l|l|}
\hline \multirow{2}{*}{ Varieties } & \multicolumn{3}{|c|}{$\mathbf{2 0}$ DAP } & \multicolumn{3}{|c|}{ 40 DAP } \\
\cline { 2 - 7 } & $\mathbf{1 0 0} \%$ F.C & $\mathbf{5 0} \%$ F.C & $\begin{array}{c}\text { Variety } \\
\text { Mean }\end{array}$ & $\mathbf{1 0 0} \%$ F.C & $\mathbf{5 0} \%$ F.C & $\begin{array}{c}\text { Variety } \\
\text { Mean }\end{array}$ \\
\hline PKM- 1 & 4.00 & 4.00 & $\mathbf{4 . 0 0}$ & 13.00 & 28.00 & $\mathbf{2 0 . 5 0}$ \\
\hline Arka Meghali & 3.00 & 3.00 & $\mathbf{3 . 0 0}$ & 21.00 & 10.00 & $\mathbf{1 5 . 5 0}$ \\
\hline Arka Vikas & 2.00 & 2.00 & $\mathbf{2 . 0 0}$ & 10.00 & 18.00 & $\mathbf{1 4 . 0 0}$ \\
\hline Treatment Mean & $\mathbf{3 . 0 0}$ & $\mathbf{3 . 0 0}$ & - & $\mathbf{1 4 . 6 7}$ & $\mathbf{1 8 . 6 7}$ & - \\
\hline & $\mathrm{T}$ & $\mathrm{V}$ & TxV & $\mathrm{T}$ & $\mathrm{V}$ & TxV \\
\hline S.Em \pm & 0.21 & 0.26 & 0.36 & 0.35 & 0.43 & 0.61 \\
\hline C.D at 5\% & 0.59 & 0.73 & 1.03 & 1.00 & 1.23 & 1.74 \\
\hline DAP- Days after planting, F.C-Field capacity, T-Treatment, V-Variety & \\
\hline
\end{tabular}

Table.7 Effect of water stress on root length in tomato $(\mathrm{cm})$

\begin{tabular}{|l|l|l|l|l|l|l|}
\hline \multirow{2}{*}{ Varieties } & \multicolumn{5}{|c|}{$\mathbf{2 0}$ DAP } & \multicolumn{3}{|c|}{ 40 DAP } \\
\cline { 2 - 7 } & $\mathbf{1 0 0} \%$ F.C & $\mathbf{5 0} \%$ F.C & $\begin{array}{c}\text { Variety } \\
\text { Mean }\end{array}$ & $\mathbf{1 0 0} \%$ F.C & $\mathbf{5 0} \%$ F.C & $\begin{array}{c}\text { Variety } \\
\text { Mean }\end{array}$ \\
\hline PKM- 1 & 17.00 & 20.40 & $\mathbf{1 8 . 7 0}$ & 25.80 & 32.60 & $\mathbf{2 9 . 2 0}$ \\
\hline Arka Meghali & 15.27 & 17.73 & $\mathbf{1 5 . 5 0}$ & 39.60 & 22.60 & $\mathbf{3 1 . 1 0}$ \\
\hline Arka vikas & 17.13 & 16.20 & $\mathbf{1 6 . 6 7}$ & 21.60 & 30.80 & $\mathbf{2 6 . 2 0}$ \\
\hline Treatment Mean & $\mathbf{1 6 . 4 7}$ & $\mathbf{1 . 4 4}$ & - & 29.00 & 28.67 & - \\
\hline & $\mathrm{T}$ & $\mathrm{V}$ & $\mathrm{TxV}$ & $\mathrm{T}$ & $\mathrm{V}$ & $\mathrm{TxV}$ \\
\hline S.Em \pm & 0.61 & 0.74 & 1.05 & 0.23 & 0.28 & 0.40 \\
\hline C.D at 5\% & 1.73 & 2.11 & 2.99 & 0.66 & 0.81 & 1.14 \\
\hline DAP- Days after planting, F.C-Field capacity, T-Treatment, V-Variety & \\
\hline
\end{tabular}

Table.8 Effect of water stress on Root volume in Tomato $\left(\mathrm{cm}^{3}\right)$

\begin{tabular}{|c|c|c|c|c|c|c|}
\hline \multirow[b]{2}{*}{ Varieties } & \multicolumn{3}{|c|}{20 DAP } & \multicolumn{3}{|c|}{40 DAP } \\
\hline & $100 \%$ F.C & $50 \%$ F.C & $\begin{array}{c}\text { Variety } \\
\text { Mean }\end{array}$ & $100 \%$ F.C & $50 \%$ F.C & $\begin{array}{c}\text { Variety } \\
\text { Mean }\end{array}$ \\
\hline PKM- 1 & 1.90 & 2.85 & 2.37 & 6.00 & 20.00 & 13.00 \\
\hline Arka Meghali & 1.70 & 1.60 & 1.65 & 10.00 & 8.00 & 9.00 \\
\hline Arka vikas & 1.05 & 1.70 & 1.38 & 6.00 & 10.00 & 8.00 \\
\hline Treatment Mean & 1.55 & 2.05 & - & 7.33 & 12.67 & - \\
\hline & $\mathrm{T}$ & $\mathrm{V}$ & $\mathrm{TxV}$ & $\mathrm{T}$ & $\mathrm{V}$ & TxV \\
\hline S.Em \pm & 0.07 & 0.08 & 0.12 & 0.36 & 0.45 & 0.63 \\
\hline C.D at 5\% & 0.19 & 0.22 & 0.33 & 1.03 & 1.27 & 1.79 \\
\hline
\end{tabular}




\section{Root characters}

\section{Root weight}

Among the varieties significantly highest fresh root weight was recorded in PKM-1 and the lowest was in Arka Vikas at 20 and 40 days after planting (Table 6). However, there was no significant difference between the two levels of irrigation at 20 days after planting. Whereas, marked difference was observed at 40 days after planting. Among the two levels of irrigation, PKM-1 and Arka Vikas recorded higher root weight of 28 and $18 \mathrm{~g} \mathrm{plant}^{-1}$ respectively at $50 \%$ field capacity.

From the results it can be inferred that, though Arka Meghali recorded higher mean value next to PKM-1, the performance was conspicuous only at $100 \%$ field capacity and there was a reduction in the root weight at $50 \%$ field capacity revealing the fact that the water requirement would be more for Arka Meghali as compared to PKM-1 and Arka Vikas. It was also observed that there was 200 per cent increase in the root weight in PKM-1 and Arka Vikas at $50 \%$ field capacity as compared to $100 \%$ field capacity and reverse was the case in Arka Meghali.

\section{Root length}

At 20 days after planting there was no significant difference among the varieties at $100 \%$ field capacity whereas the variety PKM-1 differed significantly as compared to other varieties under water stress by recording root length of $20.40 \mathrm{~cm}$ (Table 7).

The variety mean indicated significant difference only between PKM-1 and Arka Meghali. At 40 days after planting, Arka Meghali recorded higher root length $(39.60 \mathrm{~cm})$ at $100 \%$ field capacity followed by PKM$1(25.80 \mathrm{~cm})$ and Arka Vikas $(21.60 \mathrm{~cm})$, whereas at $50 \%$ field capacity PKM-1 recorded the highest root length $(32.60 \mathrm{~cm})$ and the lowest $(22.60 \mathrm{~cm})$ was in Arka Meghali.
From the results, it was noticed that root growth was not interrupted in PKM-1at $50 \%$ field capacity at both the stages of observation. Whereas in the case of Arka Vikas the root length was less at 20 days after planting at $50 \%$ field capacity but on the other hand it recorded longer roots as compared to $100 \%$ field capacity at 40 days after planting. Whereas, in the case of Arka Meghali, longer roots was recorded at $50 \%$ field capacity at 20 days after planting but the root length was considerably reduced at $50 \%$ field capacity at 40 days after planting. The above observation indicates that the performance of PKM-1 is not mitigated by water stress as it performed significantly higher at $50 \%$ field capacity as compared to $100 \%$ field capacity. It also showcases its suitability to grow under water stress conditions. Whereas in the case of Arka Megahli, though the initial growth at 20 days after planting was higher at $50 \%$ field capacity, the root length was significantly affected at $50 \%$ field capacity at 40 days after planting.

This once again gives an indication that, the performance of Arka Meghali might be reduced at reduced level of irrigation on ontogeny of the crop which may have the impact in the final output. On the other hand, the variety Arka Vikas, though longer roots were recorded $100 \%$ field capacity at 20 days after planting, there was shift at 40 days after planting as $50 \%$ field capacity recorded higher root length as compared to $100 \%$ making it suitable for cultivation under water stress condition.

\section{Root volume}

At 20 days after planting, the root volume was higher at 50\% Field capacity in PKM-1(2.85 $\mathrm{cm}^{3}$ ) followed by Arka Vikas $\left(1.70 \mathrm{~cm}^{3}\right)$. In the case of Arka Meghali the root volume was higher $\left(1.70 \mathrm{~cm}^{3}\right)$ at $100 \%$ field capacity and there was a reduction at $50 \%$ field capacity, similar trend was noticed at 40 days after planting. Whereas, the varieties, PKM-1 and Arka Vikas recorded higher root volume at 50\% field capacity with a root volume of 20 and 10 $\mathrm{cm}^{3}$ respectively (Table 8 ). 
From the results, it can be inferred that root growth of the varieties of PKM-1 and Arka Vikas was unhindered due to the reduction in the water application, whereas Arka Meghali requires the field condition to be maintained at $100 \%$ field capacity.

Among the varieties PKM-1 recorded higher root volume both at 20 and 40 days after planting followed by Arka Meghali and Arka Vikas. The varieties PKM-1 and Arka Vikas can perform better under moisture stress conditions, whereas the possibility of growing Arka Megahli needs further investigation finding its suitability under water stress condition.

From the above study it can be concluded that among the three cultivars, Arka Vikas and PKM-1 are comparatively tolerant towards water stress at 40 days as compared to Arka Meghali, which is considered to be the critical growth period where the water stress affects the growth and yield of tomato (Nuruddin, 2001). Root architecture is an important parameter to anchor water stress situation which clearly indicates proficient water use efficiency. The variety PKM-1 which is very popular variety commercially grown not only in Tamil Nadu but also in adjoining states has significantly pronounced for improved water use efficiency. This variety followed by Arka Vikas showed the next best. Nevertheless, these preliminary root architecture studies potentially a tool to short list the available commercial varieties for further utilization under water stress condition and no doubt there is a scope for in depth analysis for managing environmental vagaries including drought implicated situations in future.

\section{References}

Anonymous.2013. National Horticulture Board data base

Alaoui, S.M., Salghi, R., Abouatallah, A., Jaouhari, N., Hammouti, B. 2014. Impact of Drip Irrigation Scheduling on Vegetative Parameters in Tomato (Lycopersicon esculentum Mill.) Under Unheated Greenhouse. Int. Journal of Engineering Research and Applications. 4(1):71-76

Aragon, E. L. 1988. Improved fertilizer and water management practices for irrigated and rainfed lowland rice. Ph.D. Diss., Univ. Philipp, Los Banos, Philippines.

Brdar-Jokanovic M., Girek, Z., Pavlovic, S., Ugrinovic, M., Zdravkovic. J.2014. Shoot and root dry weight in drought exposed tomato populations. Genetika, Vol 46, No. 2, 495504.

Ingram, K. T. and Yambao. E. B.1988. Rice sensitivity to water deficit at different growth stages. Int. Rice Res. Newsl, 13 (5), 16-17.

Kirnak, H., Kaya, C., Tas, I. and Higgs, D. 2001. The influence of water deficit on vegetative growth, physiology, fruit yield and quality in eggplants. Bulg. J.Plant Physiol. 27(3-4), 3446.

May, D. M.1993. Moisture Stress to Maximize Processing Tomato Yield and Fruit Quality, ISHS Acta Horticulture 335: International Symposium on Irrigation of Horticultural Crops 1 April 1993.

Morison, J.I.L., Baker, N.R., Mullineaux, P.M. and Davies, W.J.2008. Improving water use in Crop Production. Phil. Trans. R. Soc. B, 363:639-658

Nuruddin, M.M. 2001. Effects of water stress on tomato at different growth stages, Thesis MSc., Mc Gili University, Macdonald Campus, Montreal, Canada.

Nyabundi, J. O. and Hsia, T.C. 2009. Effects of water stress on growth and yield of fieldgrown tomatoes. H.Biomass partitioning between vegetative and productive growth. $E$. Afr. Agric. J. 55(2), 53-61.

Shamsul, H., Syed, A.H., Qazi, F. and Agil, A. 2008. Growth of tomato (Lycopersicon esculentum) in response to salicyclic acid under water stress. Journal of plantinteractions, 3(4), 297304.

\section{How to cite this article:}

Senthilkumar, M., A.T. Sadashiva and Laxmanan, V. 2017. Impact of Water Stress on Root Architecture in Tomato (Solanum lycopersicum Mill). Int.J.Curr.Microbiol.App.Sci. 6(7): 2095-2103. doi: https://doi.org/10.20546/ijcmas.2017.607.247 